\title{
Study of the Performance of Stainless Steel A-TIG Welds
}

\author{
S.W. Shyu, H.Y. Huang, K.H. Tseng, and C.P. Chou
}

(Submitted August 9, 2006; in revised form March 30, 2007)

\begin{abstract}
The purpose of the present work was to investigate the effect of oxide fluxes on weld morphology, arc voltage, mechanical properties, angular distortion and hot cracking susceptibility obtained with TIG welding, which applied to the welding of $5 \mathrm{~mm}$ thick austenitic stainless steel plates. A novel variant of the autogenous TIG welding process, oxide powders $\left(\mathrm{Al}_{2} \mathrm{O}_{3}, \mathrm{Cr}_{2} \mathrm{O}_{3}, \mathrm{TiO}_{2}, \mathrm{SiO}_{2}\right.$ and $\left.\mathrm{CaO}\right)$ was applied on a type 304 stainless steel through a thin layer of the flux to produce a bead on plate welds. The experimental results indicated that the increase in the penetration is significant with the use of $\mathrm{Cr}_{2} \mathrm{O}_{3}, \mathrm{TiO}_{2}$, and $\mathrm{SiO}_{2}$. A-TIG welding can increase the weld depth to bead-width ratio, and tends to reduce the angular distortion of the weldment. It was also found that A-TIG welding can increase the retained delta-ferrite content of stainless steel 304 welds and, in consequence, the hot-cracking susceptibility of as-welded is reduced. Physically constricting the plasma column and reducing the anode spot are the possible mechanism for the effect of certain flux on A-TIG penetration.
\end{abstract}

Keywords A-TIG, stainless steel, oxide flux, penetration

\section{Introduction}

Gas tungsten arc welding (GTAW), also known as tungsten inert gas (TIG) welding which uses an arc between a nonconsumable tungsten electrode and the workpieces to be welded under a shielding gas is an extremely important arc welding process. It has become a popular choice of welding process when a high level of weld quality or considerable precision welding operation is required. However the potential problems of TIG welding process lie in the limited thickness of material which can be welded in a single pass, poor tolerance to some material composition and the low productivity (Ref 1). If the welding current is increased in an attempt to increase the penetration, the weld becomes excessively wide with proportionally little gain in the penetration.

Improvements in the penetration have long been sought in many arc-welding processes. One of the most notable techniques is the use of activating flux in TIG welding process. Activated tungsten inert gas (A-TIG) welding process that increases the penetration was first proposed by Paton Electric Welding Institute in the 1960s (Ref 2-4). Activating flux is a mixture of inorganic material suspended in a volatile medium. A thin layer of flux is applied on the surface of the joint to be welded by brush before welding. The United States Navy Joining Center has been successfully used in everyday production to reduce the cost and improve the quality of Navy

S.W. Shyu and C.P. Chou, Department of Mechanical Engineering, National Chiao Tung University, Hsinchu 300, Taiwan; and S.W. Shyu, Department of Mechanical Engineering, National United University, Miaoli 360, Taiwan; and H.Y. Huang, Department of Technology, Ten Gun Industrial Co., Ltd, Taichung 407, Taiwan; and K.H. Tseng, Department of R\&D, Aritex Products Co., Ltd, Kaohsiung 831, Taiwan. Contact e-mail: sws@nuu.edu.tw. ships and aircraft, using A-TIG technique that was developed by Edison Welding Institute (Ref 5). A-TIG technique makes it possible to intensify the conventional TIG practices for joining the thickness of $8-10 \mathrm{~mm}$ by single pass full penetration welds, with no edge preparation, instead of multipass procedures. In fact, the penetration capability is up to $300 \%$ compared with the conventional TIG welding process, and the heat-to-heat variations in base metal compositions can be avoided when using the activating flux (Ref 6-9).

The current theory on the effect of activating flux on penetration is that the flux changes the surface tension in the weld pool so that the fluid flow is changed, and tends to increase the penetration. However, only a few data are available in the open literature about the effect of welding arc on A-TIG penetration. Such data are very important to determine the penetration improvement function of the activating flux. In the present work, five kinds of oxide powders were used to study systematically the effect of activating flux on weld morphology, arc voltage, mechanical properties, angular distortion, and hot cracking susceptibility in stainless steel 304 welds. Furthermore, the relational behavior model between plasma arc and anode spot in TIG welding produced with activating flux, in comparison with the conventional TIG welding process, are presented.

\section{Experimental Procedure}

Austenitic stainless steel 304 with chemical compositions and mechanical properties listed in Table 1 was used. Plates $5 \mathrm{~mm}$ in thickness were cut into strips of $150 \times 150 \mathrm{~mm}$, which were roughly polished with 400 grit (silicon carbide) flexible abrasive paper to remove surface impurities, and then cleaned with acetone. Activating flux was prepared using the five kinds of oxide fluxes (The $\mathrm{Al}_{2} \mathrm{O}_{3}, \mathrm{CaO}, \mathrm{TiO}_{2}, \mathrm{Cr}_{2} \mathrm{O}_{3}$, and $\mathrm{SiO}_{2}$ fluxes used were packed in powdered form) by mixing them with acetone, and a layer less than $0.2 \mathrm{~mm}$ thick was applied to the surface of the joint to be welded by means of a brush before TIG welding. Figure 1 is a schematic diagram of TIG welding 
Table 1 Chemical composition (wt\%, balance Fe) and mechanical properties of experimental austenitic stainless steel

\begin{tabular}{cccccccccc}
\hline $\mathbf{C}$ & $\mathbf{S i}$ & $\mathbf{M n}$ & $\mathbf{P}$ & $\mathbf{S}$ & $\mathbf{C r}$ & $\mathbf{N i}$ & Yield strength, MPa & Elastic modulus, GPa & Poisson's ratio \\
\hline 0.07 & 0.51 & 1.30 & 0.026 & 0.013 & 18.7 & 8.16 & 290 & 193 & 0.25 \\
\hline
\end{tabular}

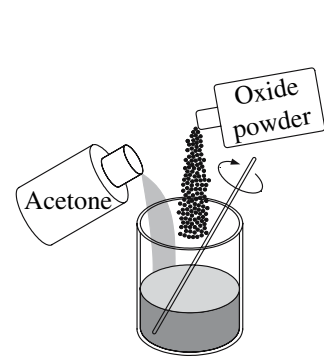

(a) Mixing

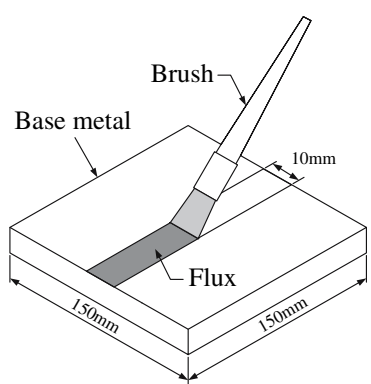

(b) Coating
Fig. 1 Schematic diagram of TIG welding produced with activating flux

produced with activating flux. An autogenous TIG welding was conducted on a type 304 stainless steels to produce a bead on plate welds. A machine-mounted torch with standard $2 \%$ thoriated tungsten electrode (3.2 mm diameter) was used. The electrode tip configuration was a blunt point with a $60^{\circ}$ include angle. Welding parameters used in the present work are given in Table 2. During welding process, a CCD camera system was used to observe the tungsten electrode, the welding arc, and the weld pool.

The ferrite number (FN) was measured using a calibrating magnetic instrument with a Ferritscope M10B-FE. To minimize measurement errors due to the weldment inhomogeneity, the average value of seven measurements from different locations along the as-welded surface was recorded.

Figure 2 is a schematic diagram of welding distortion measurement. A position fixed hole was drilled at the back of points $\mathrm{P}_{1}, \mathrm{P}_{2}$, and $\mathrm{P}_{3}$, and a pillar was attached to each hole. Three pillars (one stable, the other two adjustable) were used to adjust the horizontal level. Prior to measuring, five sets of measuring positions were determined on both the left side (A-E) and right side (F-J) of the as-welded surface along the $y$-axis. During the measurement, the stage was moved along the $x$-axis by $50 \mathrm{~mm}$, and a vertical displacement $Z$ was obtained. The angular distortion value $\theta$ can be derived from the equation

$\theta=\tan ^{-1} \frac{Z}{50}$

Finally, the five positions on either side of the welds were averaged, and then added together to give the angular distortion value.

In the present work, the hot cracking susceptibility was evaluated by spot varestraint test (Ref 10-12). The welding conditions were $80 \mathrm{~A}$ arc current with $8 \mathrm{~s}$ arc time in $3 \mathrm{~mm}$ thick stainless steel plate, and the arc length was maintained at $1.6 \mathrm{~mm}$. Hot cracking occurred in both the weld metal and heat-affected zone. In this evaluation of the hot cracking susceptibility, the total cracking length in the weld metal was normalized on the basis of the weld pool diameter. Figure 3 shows the spot varestraint test method in a schematic form.
Longitudinal tensile and Vickers hardness tests were used to examine the metallurgical properties of A-TIG stainless steel welds. Longitudinal tensile tests of three specimens from each welding procedure combination were used to determine the strength and ductility of the weldments. The configuration and size of the tensile specimens were in accordance with ASTM E8. Tensile fracture morphology of the weldment was also analyzed by means of a scanning electron microscopy. Vickers hardness in the weld metal was measured under a load of $1.96 \mathrm{~N}$ for $15 \mathrm{~s}$. An optical microscope was used to measure the dimensions of the weld depth and bead width. All metallographic specimens were prepared by mechanical lapping, grinding, and polishing to a $0.3 \mu \mathrm{m}$ finish, followed by etching in a solution of $10 \mathrm{~g} \mathrm{CuSO}_{4}+50 \mathrm{ml} \mathrm{HCl}+50 \mathrm{ml}$ $\mathrm{H}_{2} \mathrm{O}$.

\section{Results and Discussion}

\subsection{Effect of Oxide Fluxes on Weld Morphology}

Figure 4 shows the cross-sections of TIG welds without and with flux in $5 \mathrm{~mm}$ thick stainless steel 304 plates. There is significant variation in weld depth and bead width of A-TIG weld morphology. The increases in weld depth and the decrease in bead width are significant with use of the $\mathrm{Cr}_{2} \mathrm{O}_{3}, \mathrm{TiO}_{2}$ and $\mathrm{SiO}_{2}$, and have the particular shape of a peanut shell. In the present work, the greatest improvement function in the penetration capability occurred with the use of $\mathrm{SiO}_{2}$, up to $220 \%$, compared with the conventional TIG welding. However, the $\mathrm{CaO}$ has no effect on A-TIG penetration.

It can also be seen in Fig. 4 that TIG welding with $\mathrm{Cr}_{2} \mathrm{O}_{3}$, $\mathrm{TiO}_{2}$ and $\mathrm{SiO}_{2}$ can significantly increase the weld depth to bead width ratio. According to previous investigations (Ref 13, 14), a greater weld depth to bead width ratio is a characteristics of the increased energy density of the heat source, and thereby the high degree of energy concentration during TIG welding process.

Although a commonly agreed mechanism for increased A-TIG penetration has yet to be found, it has frequently been observed in TIG and plasma welding that using activating flux can constrict the welding arc, and tends to increase the penetration (Ref 1-3). The major effect of activating flux appears to be on the characteristic of the welding arc rather than on the direction of the fluid flow (Ref 1, 8, 9). In arcing without flux and with $\mathrm{SiO}_{2}$ composition (shown in Fig. 5), the central part of the welding arc shows clearly in a glowing zone occupying almost the entire arc length. The zone is regarded as the plasma column, which forms by the current carried by the electrons and positive ions produced by thermal ionization of the shielding gas. It can be seen in that TIG welding arc with $\mathrm{SiO}_{2}$ shows a constriction in plasma column diameter compared with the conventional TIG welding arc at the same current level. Constriction of the plasma column increases 


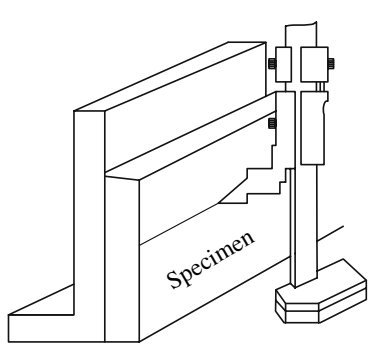

Scribing

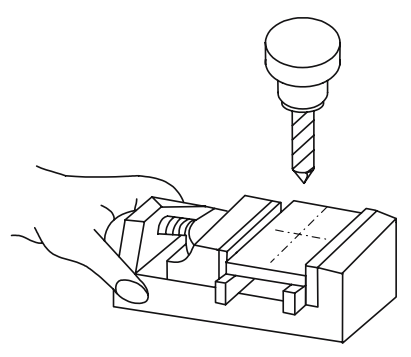

Drilling

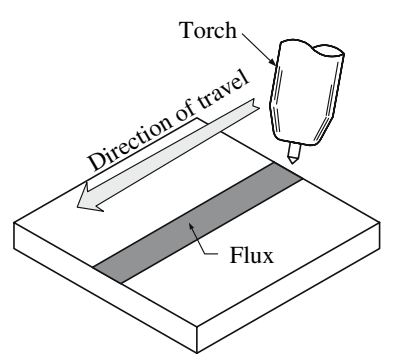

Welding

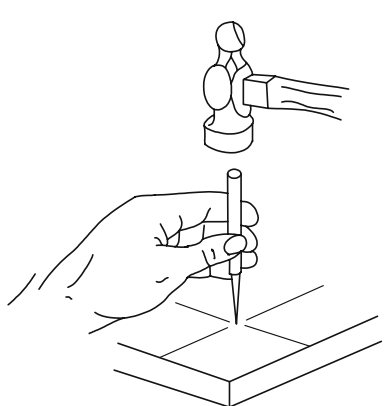

Locating

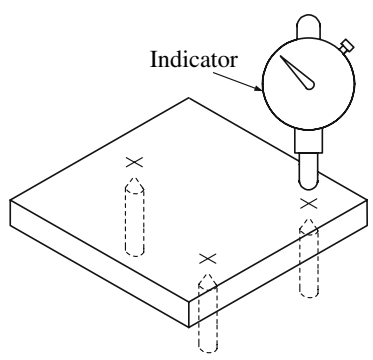

Leveling

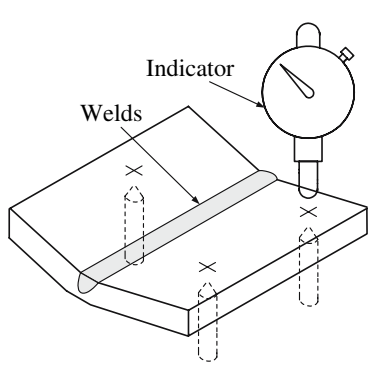

Measuring

(a) Measuring step

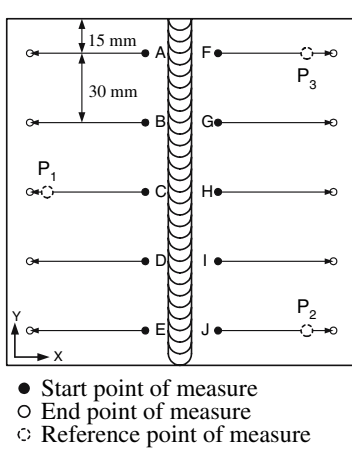

(b) Measuring position

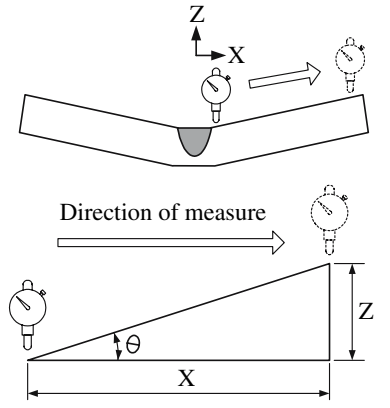

(c) Measuring theory

Fig. 2 Schematic diagram of welding distortion measurement

Table 2 Welding parameters for autogenous TIG welding experiments

\begin{tabular}{ll}
\hline Welding current & $150 \mathrm{~A}$ \\
Travel speed & $150 \mathrm{~mm} / \mathrm{min}$ \\
Arc length & $3 \mathrm{~mm}$ \\
Shielding gas & Pure argon \\
Gas flowrate & $10 \mathrm{~L} / \mathrm{min}$ \\
\hline
\end{tabular}

the current density in the arc root, and a more focused arc increase in A-TIG penetration can be achieved compared with the conventional TIG welds.

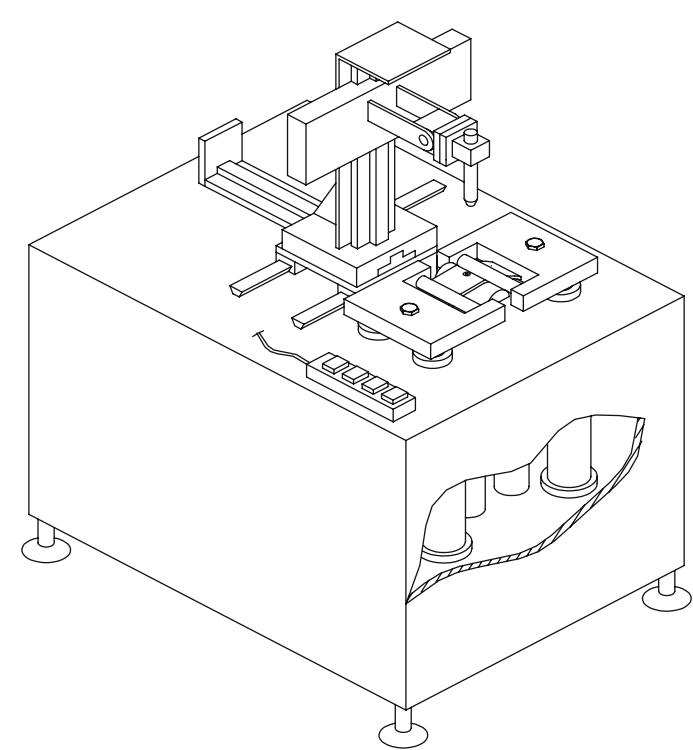

(a)

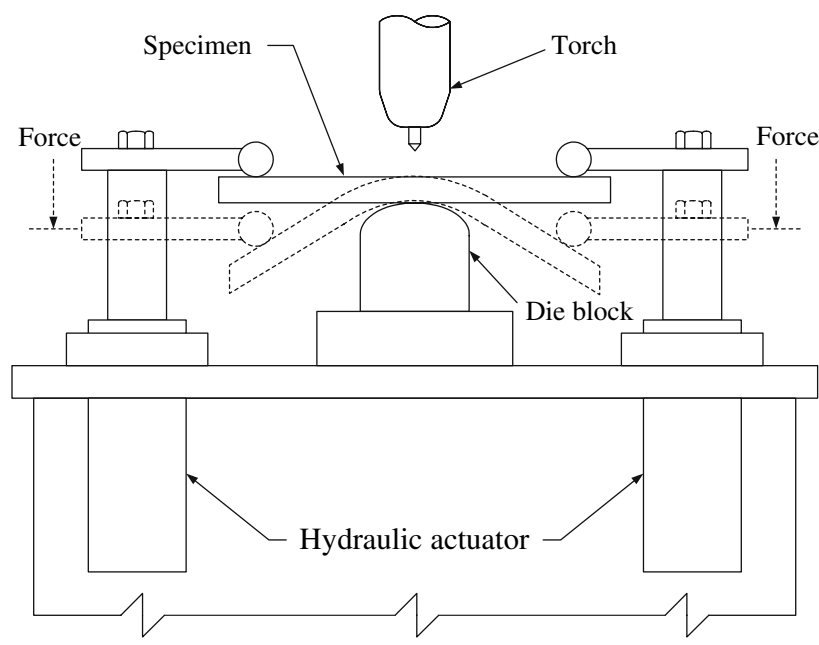

(b)

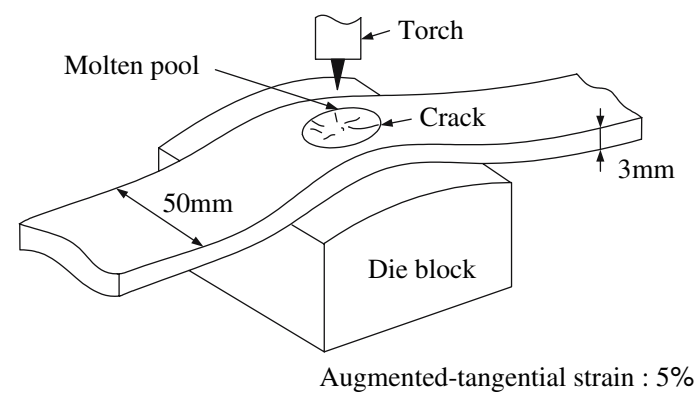

(c)

Fig. 3 Schematic diagram of spot varestraint test

Other factors, such as anode spot, can also affect the weld morphology. Because the conductivity of the flux is much lower than that of the metal vapors, and the melting and boiling point of the flux are higher than that of the weld metal, the metal evaporation will be only generated in the central regions of the welding arc, where the temperature is higher than the 


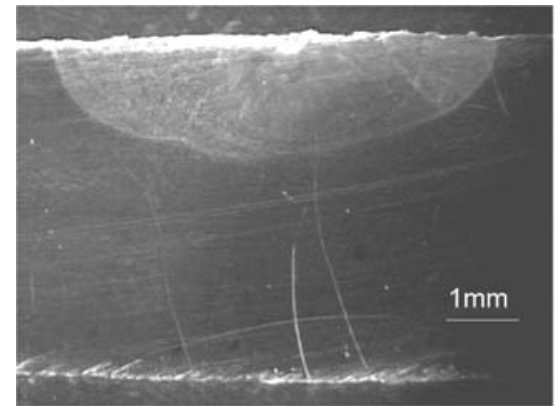

(a) With $\mathrm{Al}_{2} \mathrm{O}_{3}$ flux $(\mathrm{D}=1.37, \mathrm{~W}=6.78, \mathrm{D} / \mathrm{W}=0.20)$

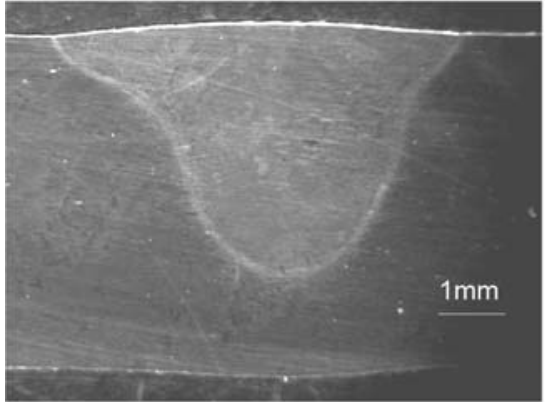

(c) With $\mathrm{TiO}_{2}$ flux

$(\mathrm{D}=3.68, \mathrm{~W}=6.16, \mathrm{D} / \mathrm{W}=0.60)$

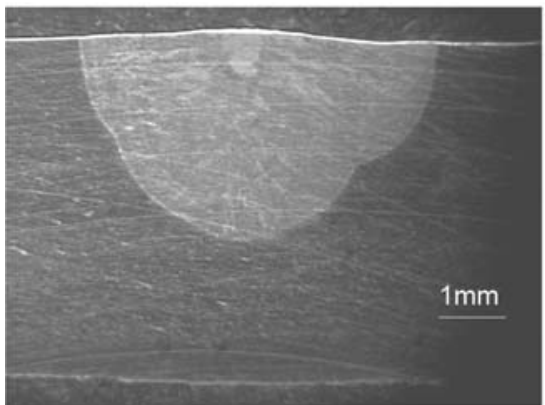

(e) With $\mathrm{CaO}$ flux

$(\mathrm{D}=2.60, \mathrm{~W}=5.46, \mathrm{D} / \mathrm{W}=0.48)$

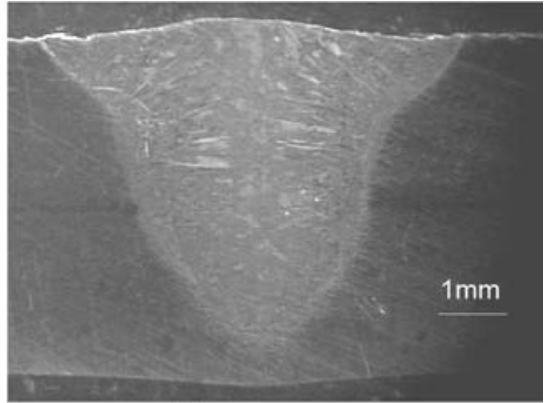

(b) With $\mathrm{Cr}_{2} \mathrm{O}_{3}$ flux

$(\mathrm{D}=4.80, \mathrm{~W}=6.39, \mathrm{D} / \mathrm{W}=0.75)$

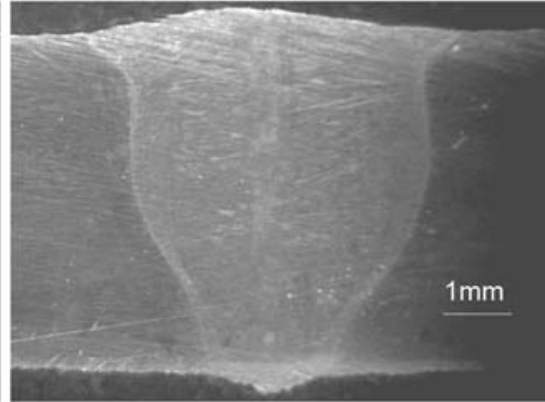

(d) With $\mathrm{SiO}_{2}$ flux

$(\mathrm{D}=5.03, \mathrm{~W}=5.58, \mathrm{D} / \mathrm{W}=0.90$

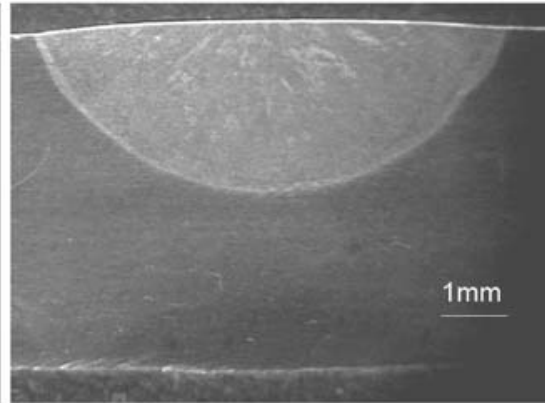

(f) Without flux

$(\mathrm{D}=2.25, \mathrm{~W}=7.24, \mathrm{D} / \mathrm{W}=0.31)$

Fig. 4 Effect of oxide fluxes on weld morphology

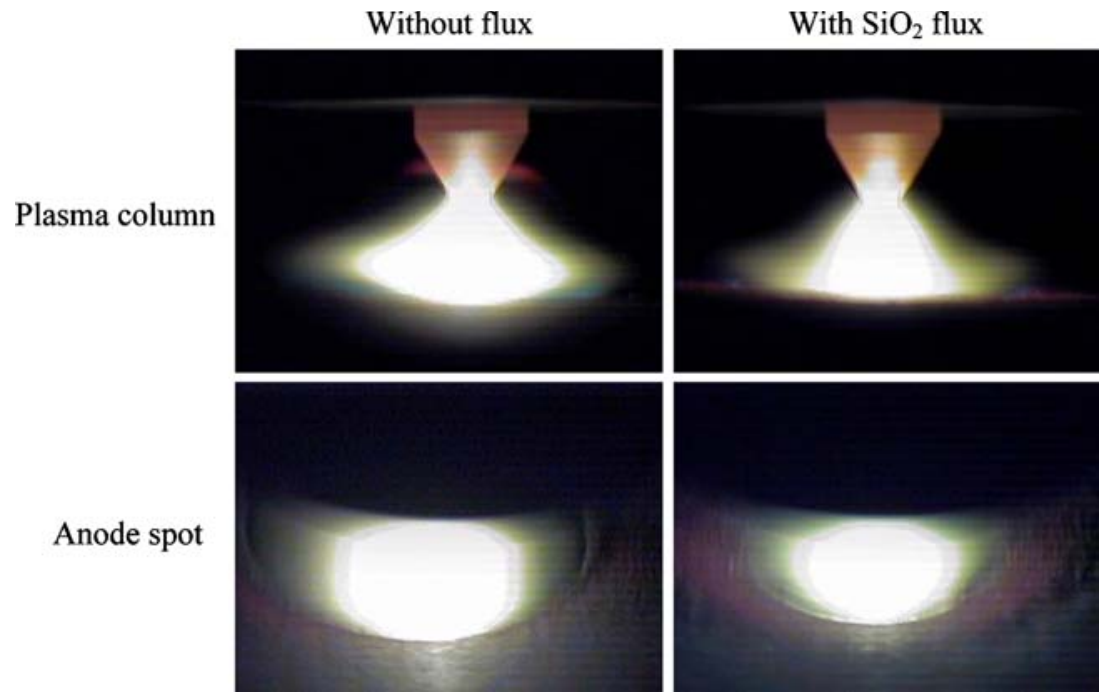

Fig. 5 Effect of TIG welding without and with flux on plasma column and anode spot 
dissociation temperature of the flux compounds, leading to a reduction in the conductivity area of the anode spot. It can also be seen in that TIG weld pool with $\mathrm{SiO}_{2}$ shows a reduction in the anode spot compared with the conventional TIG welds at the same current level.

On the basis of the present results, it is considered that the plasma column and the anode spot play a major role in determining A-TIG weld morphology. When using A-TIG welding, physically constricting the plasma column and reducing the anode spot, and tends to increase the energy density of the heat source and electromagnetic force of the weld pool, resulting in a relatively narrow and deep weld morphology compared with the conventional TIG welding. Although further investigation is still needed to understand the mechanisms, the present work has potentially demonstrated the effect of specific flux on A-TIG penetration.

It should be mentioned that the $\mathrm{Al}_{2} \mathrm{O}_{3}$ led to the deterioration in the penetration and excessive slag compared with the conventional TIG process for stainless steel 304 welds. It can be seen in that TIG welding with use of the activating flux, which is composed of $\mathrm{Al}_{2} \mathrm{O}_{3}$ powder, appears unable to constrict the plasma column and reduce the anode spot, as indicated in Fig. 6(a) and (b), resulting in a relatively wide and shallow weld morphology compared with the conventional TIG welding. This result can be related to the aluminum oxide particles of the weld pool during TIG welding with $\mathrm{Al}_{2} \mathrm{O}_{3}$ powder as shown in Fig. 6(c). As TIG welding with $\mathrm{Al}_{2} \mathrm{O}_{3}$ produces fluid flow outwards from the center of the weld pool, the particle-free band will be formed along the edge of the weld pool, resulting in an arc wander.

\subsection{Effect of Oxide Fluxes on Arc Voltage}

In the present work, three pillars (one stable, the other two adjustable) were used to adjust the horizontal level of test

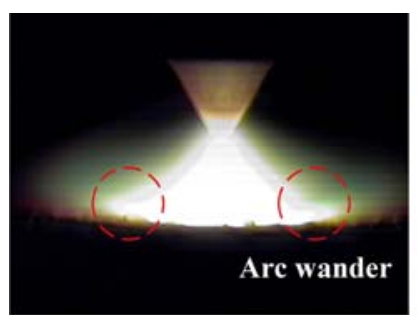

(a) Plasma column

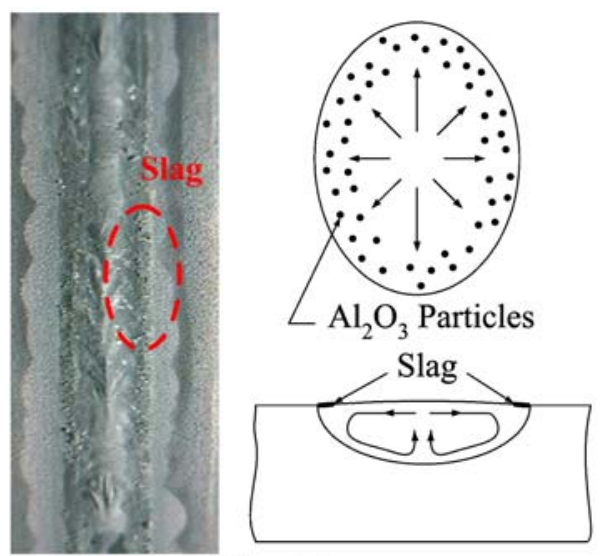

(c) Fluid flow

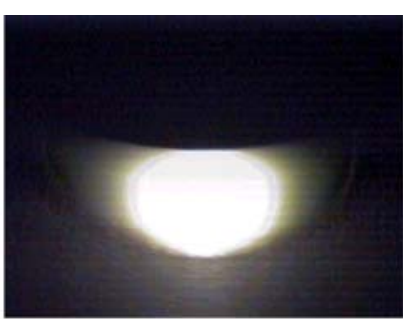

(b) Anode spot specimens before welding. During welding process, a CCD camera system was used to observe the tungsten electrode, welding arc and weld pool. It can be found that there is no significant change to the variations of electrode geometry and arc length during welding. If the welding current, travel speed, arc length, argon flowrate, and electrode geometry are constant for each weld, then the variation of distortion in the direction of the weld centerline should not be great enough to affect the arc length for a comparative study such as the present investigation.

The effect of TIG welding without and with flux on arc voltage is shown in Fig. 7. The welding current, travel speed, arc length, argon flowrate, and electrode geometry were maintained at constant value, and it was found that the arc voltage increases when TIG welding with $\mathrm{CaO}, \mathrm{TiO}_{2}, \mathrm{Cr}_{2} \mathrm{O}_{3}$, and $\mathrm{SiO}_{2}$ was used. It can be seen in Fig. 5 that A-TIG welding arc shows a constriction in plasma column diameter compared with the conventional TIG welding arc at the same welding current and arc length level. The welding arc contains a lot of free electrons. The decomposed flux additives attract electrons, causing the welding arc to constrict, results in an increase in arc voltage. In addition, the arc trailing (the arc remains behind with respect to the welding arc) in A-TIG welding (shown in Fig. 8), as a result of the effective arc length increases, and the arc voltage is consequently increased as indicated in Fig. 9(a). There is a good correlation between the measured arc voltage and arc length in TIG welding without and with flux.

Figure 9(b) shows the effect of arc length on penetration in TIG welding without and with flux. It can be seen that there is no significant change to the variations of arc length and penetration. To avoid electrode damage and obtain arc stability, A-TIG welding arc should be ignited with 2-4 mm arc length.

It should also be mentioned that the calculated heat input is proportional to the measured arc voltage, applied activating flux has the positive effect of increasing the amount of heat input per unit length in A-TIG welds.

\subsection{Effect of Oxide Fluxes on Mechanical Properties}

Figure 10 presents the experimental results for mechanical properties of TIG weldment without and with activating fluxes. It can be clearly seen that the weldment obtained by using TIG welding with $\mathrm{CaO}, \mathrm{TiO}_{2}, \mathrm{Cr}_{2} \mathrm{O}_{3}$, and $\mathrm{SiO}_{2}$ exhibits

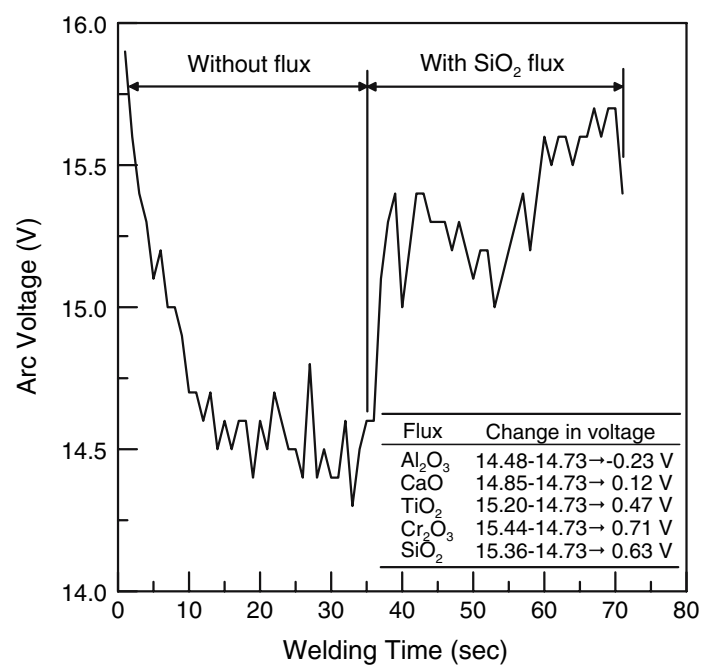

Fig. 7 Effect of oxide fluxes on arc voltage

Fig. 6 Effect of $\mathrm{Al}_{2} \mathrm{O}_{3}$ flux on welding arc and fluid flow 


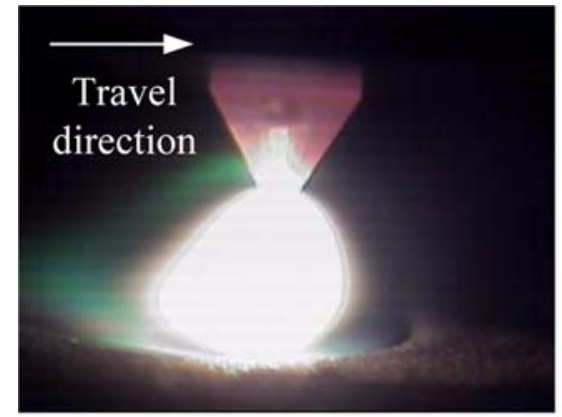

Without flux

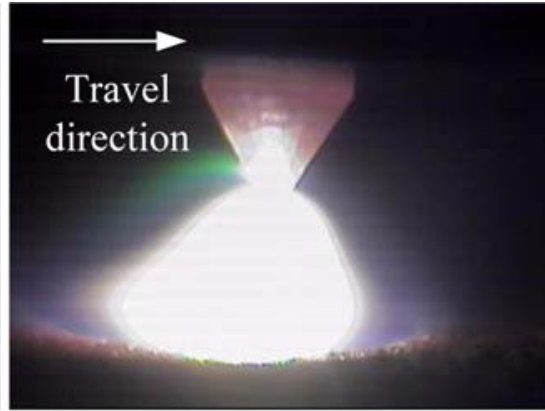

With $\mathrm{SiO}_{2}$ flux

Fig. 8 Effect of TIG welding without and with flux on arc trailing
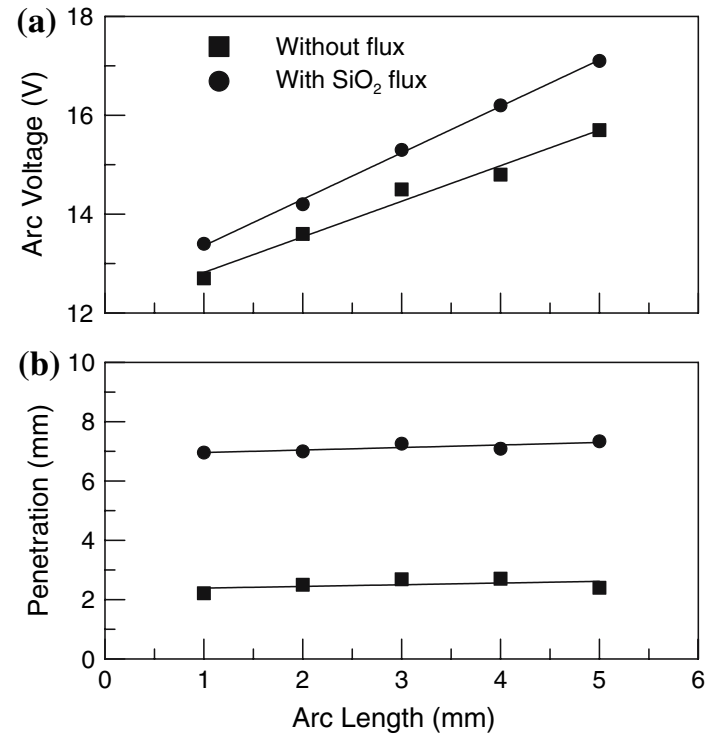

Fig. 9 Effect of arc length on arc voltage and penetration in TIG welding without and with flux

better-mechanical properties (including yield strength, ultimate tensile strength, elongation, and hardness) than those of TIG weldment without using the activating flux.

The fracture can be described as a single body being separated into pieces by imposed stress. For engineering materials there are only two possible modes of fracture, ductile and brittle. The fracture morphology of TIG weldments without and with $\mathrm{SiO}_{2}$, as indicated in Fig. 11, is the ductile dimple fracture mode.

\subsection{Effect of Oxide Fluxes on Angular Distortion}

Uneven heating through the thickness during welding of a joint causes non-uniform thermal strains that result in angular distortion. The value of angular distortion of the weldment depends on several factors, including (a) the relative penetration, and (b) the shape and dimensions of welds (Ref 15). The effect of TIG welding with various flux compositions on angular distortion of stainless steel 304 weldment is shown in Fig. 12. When TIG welding with $\mathrm{Al}_{2} \mathrm{O}_{3}$ is used, it can be seen that the weld depth is not more than the half of plate thickness. The shallow weld bead causes lower angular distortion, and with increasing the weld depth to plate
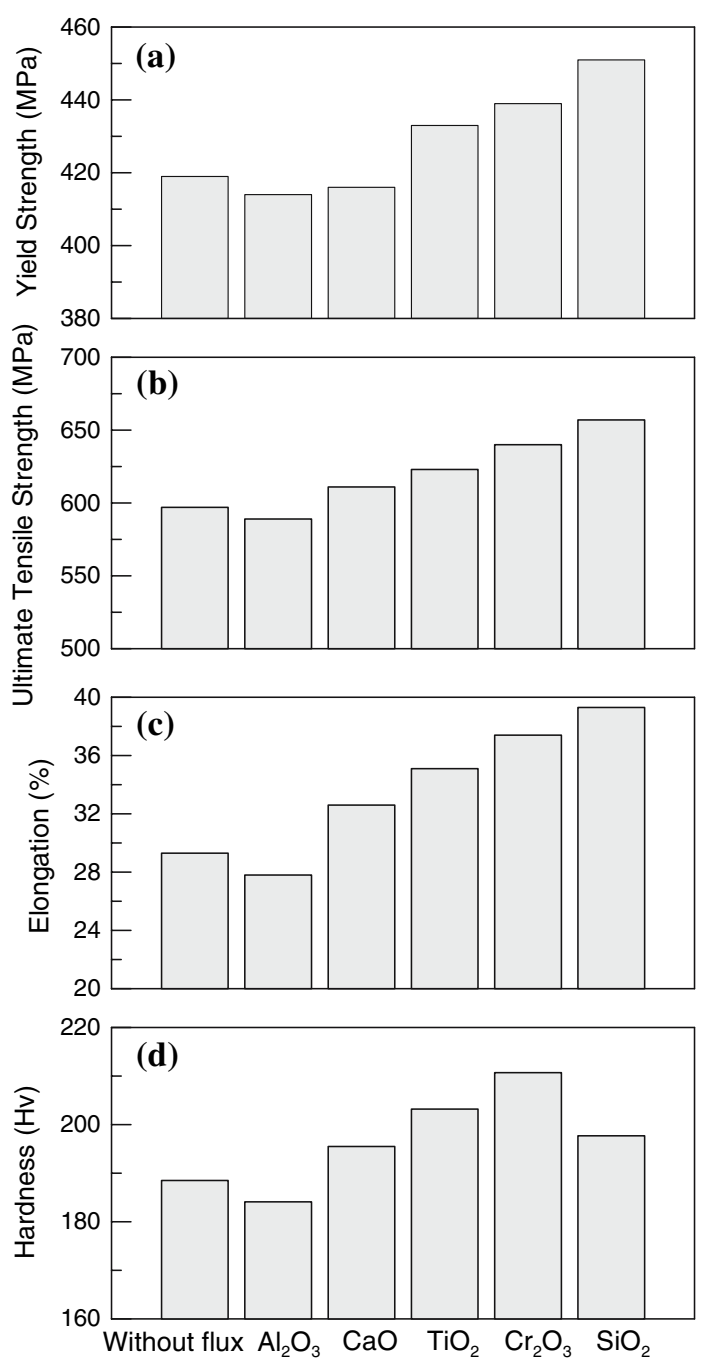

Fig. 10 Effect of oxide fluxes on mechanical properties

thickness ratio, the angular distortion of the weldment with $\mathrm{CaO}$ increases to a critical point (weld depth to plate thickness ratio equivalent to 0.5 ), and then weld depth exceeds $50 \%$ of the plate thickness, the angular distortion of the weldment with use of the $\mathrm{TiO}_{2}, \mathrm{Cr}_{2} \mathrm{O}_{3}$, and $\mathrm{SiO}_{2}$ is decreased. Because of a high degree of energy concentration during A-TIG welding process, both the weld pool and the HAZ are reduced 


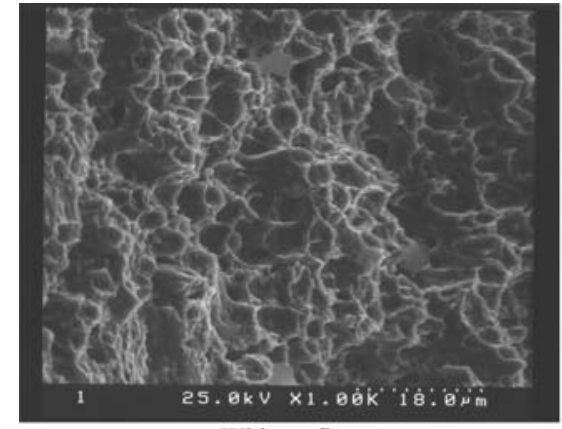

Without flux

Fig. 11 Scanning electron microscopy of fracture surface

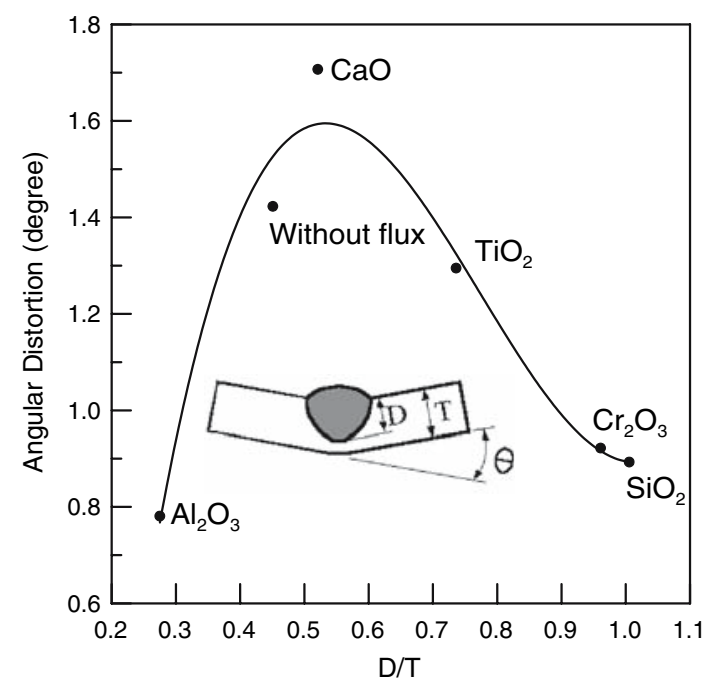

Fig. 12 Effect of weld depth to plate thickness ratio on angular distortion

(Ref 8). This contributes to a reduction in the quantity of supplied heat and, in consequence, prevents overheating of the metal; this reduces the incidence of thermal stresses and incompatible strains due to shrinkage in the thickness direction, and therefore the angular distortion of stainless steel 304 weldments can be reduced.

\subsection{Effect of Oxide Fluxes on Hot Cracking Susceptibility}

The weld metal microstructure in all the welds consisted of ferrite in an austenitic matrix (Ref 8,16$)$. The measured ferrite number of stainless steel 304 welds with various flux compositions is presented in Fig. 13(a). When TIG welding with $\mathrm{CaO}$, $\mathrm{TiO}_{2}, \mathrm{Cr}_{2} \mathrm{O}_{3}$, and $\mathrm{SiO}_{2}$ is used, the retained delta-ferrite content in weld metal is increased.

A certain amount of retained delta-ferrite in austenitic stainless steel weld metals has a beneficial effect in reducing the hot cracking susceptibility (Ref 17). The result of spot varestraint test is shown in Fig. 14. It can be seen in Fig. 13(b) that TIG welding with $\mathrm{CaO}, \mathrm{TiO}_{2}, \mathrm{Cr}_{2} \mathrm{O}_{3}$ and $\mathrm{SiO}_{2}$ can reduce total cracking length of stainless steel 304 weld metals. The result clearly indicates that the hot cracking susceptibility of stainless steel 304 as-welded can be reduced when certain flux was applied to TIG welding process.

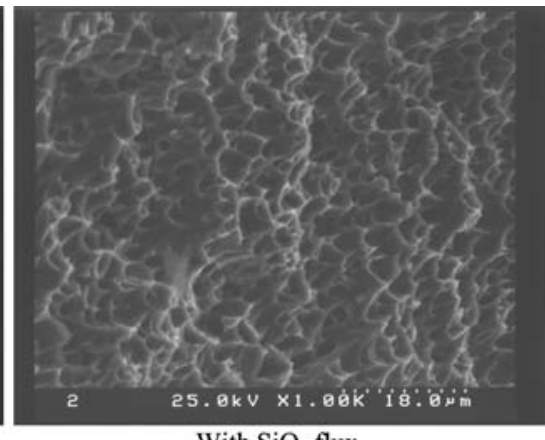

With $\mathrm{SiO}_{2}$ flux
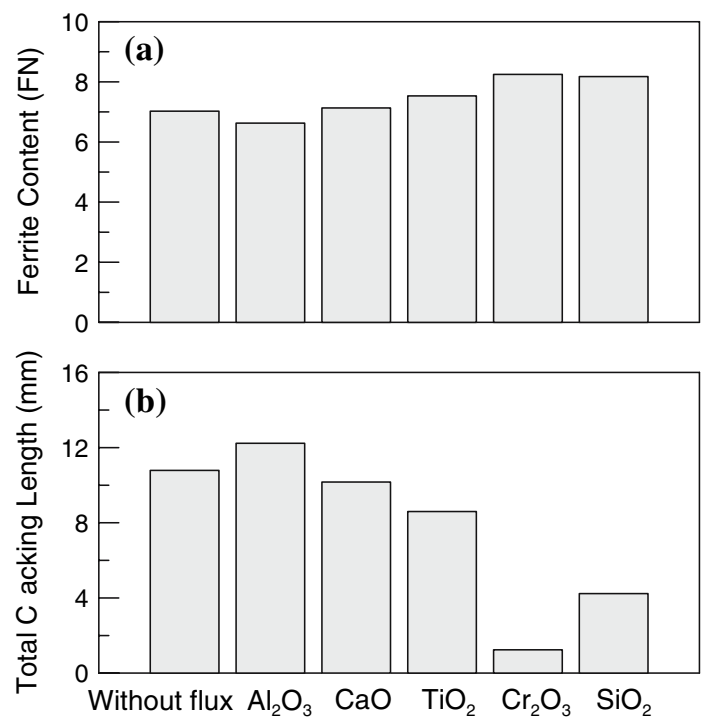

Fig. 13 Effect of oxide fluxes on hot cracking susceptibility

\section{Conclusions}

1. In the present work, the increases in weld depth and the decrease in bead width are significant with use of the $\mathrm{Cr}_{2} \mathrm{O}_{3}, \mathrm{TiO}_{2}$, and $\mathrm{SiO}_{2}$. The greatest improvement function in the penetration is with the use of $\mathrm{SiO}_{2}$, but the $\mathrm{Al}_{2} \mathrm{O}_{3}$ led to the deterioration in the penetration and excessive slag compared with the conventional TIG process for stainless steel 304 welds. The $\mathrm{CaO}$ has no effect on A-TIG penetration.

2. When using A-TIG welding, physically constricting the plasma column and reducing the anode spot, tends to increase the energy density of the heat source and electromagnetic force of the weld pool, resulting in a relatively narrow and deep weld morphology compared with the conventional TIG welding.

3. A-TIG welding can increase the arc voltage, and the amount of heat input per unit length in welds can therefore be increased.

4. A-TIG weldment exhibits better mechanical properties (including strength, ductility, and hardness) than those of TIG welding without flux. 


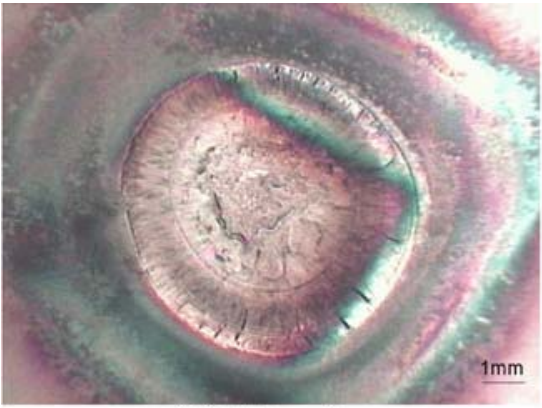

(a) Without flux

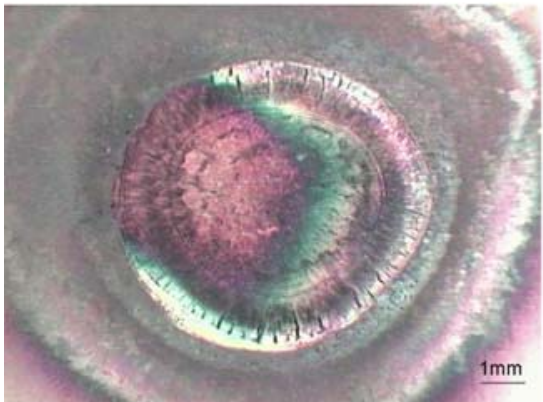

(c) With $\mathrm{CaO}$ flux

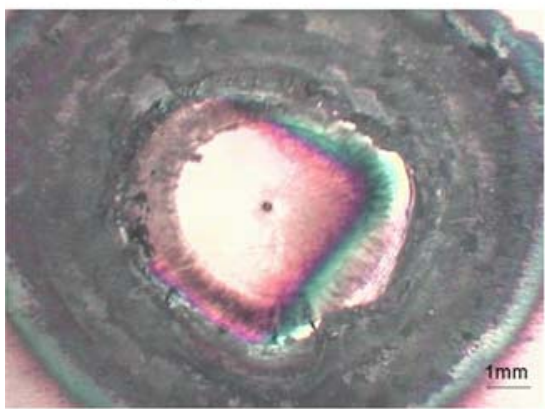

(e) With $\mathrm{Cr}_{2} \mathrm{O}_{3}$ flux

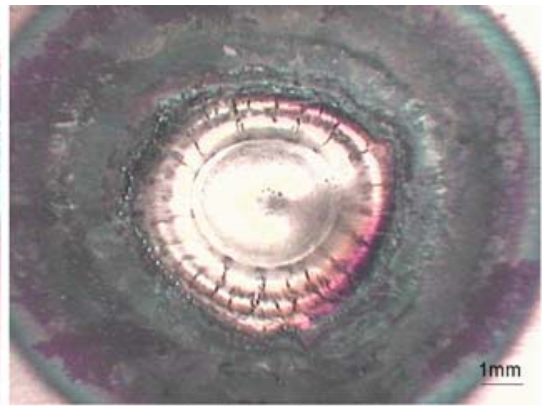

(b) With $\mathrm{Al}_{2} \mathrm{O}_{3}$ flux

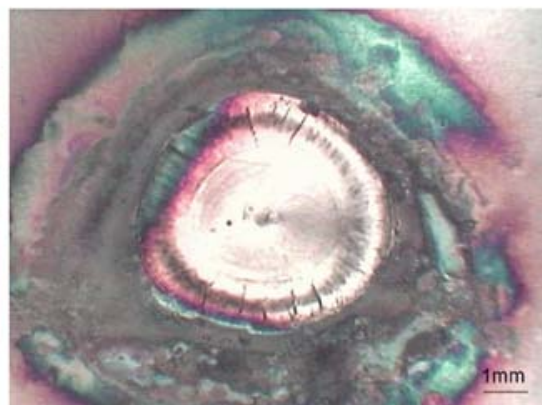

(d) With $\mathrm{TiO}_{2}$ flux

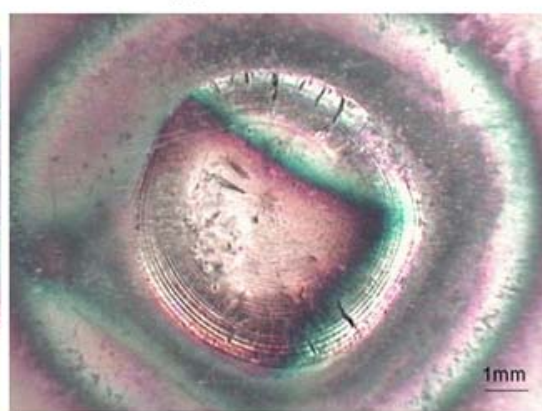

(f) With $\mathrm{SiO}_{2}$ flux

Fig. 14 Photograph of the cracks in stainless steel 304 welds

5. A-TIG welding can increase the weld depth to bead width ratio, which is characteristics of a high degree of energy concentration during welding, and then the angular distortion of the weldment can be reduced.

6. A-TIG welding can increase the retained delta-ferrite content of stainless steel welds and, in consequence, the hot cracking susceptibility of as-welded is reduced.

\section{References}

1. H.Y. Huang, S.W. Shyu, K.H. Tseng, and C.P. Chou, Effects of the Process Parameters on Austenitic Stainless Steel by TIG-flux Welding, J. Mater. Sci. Technol., 2006, 22(3), p 367-373

2. D.S. Howse and W. Lucas, Investigation into Arc Constriction by Active Fluxes for Tungsten Inert Gas Welding, Sci. Technol. Weld. Joining, 2000, 5(3), p 189-193

3. M. Tanaka, T. Shimizu, H. Terasaki, M. Ushio, F. Koshi-ishi, and C.-L. Yang, Effects of Activating Flux on Arc Phenomena in Gas Tungsten Arc Welding, Sci. Technol Weld. Joining, 2000, 5(6), p 397-402

4. M. Kuo, Z. Sun, and D. Pan, Laser Welding with Activating Flux, Sci. Technol Weld. Joining, 2001, 6(1), p 17-22
5. T. Paskell, C. Lundin, and H. Castner, GTAW Flux Increases Weld Joint Penetration, Weld. J., 1997, 76(4), p 57-62

6. C.L. Yang, S.B. Lin, F.Y. Liu, W. Lin, and Q.T. Zhang, Research on the Mechanism of Penetration Increase by Flux in A-TIG Welding, J. Mater. Sci. Technol., 2003, 19, p 225-227

7. P.J. Modenesi, E.R. Apolinário, and I.M. Pereira, TIG Welding with Single-component Fluxes, J. Mater. Process. Technol., 2000, 99(1), p 260-265

8. H.Y. Huang, S.W. Shyu, K.H. Tseng, and C.P. Chou, Evaluation of TIG-Flux Welding on the Characteristics of Stainless Steel, Sci. Technol. Weld. Joining, 2005, 10(5), p 566-573

9. H.Y. Huang, S.W. Shyu, K.H. Tseng, and C.P. Chou, Effect of A-TIG Welding on the Morphology of Stainless Steel Welds, Proceedings of 7th International Conference on Trends in Welding Research, ASM International, 2005

10. T. Ogawa and E. Tsunetomi, Hot Cracking Susceptibility of Austenitic Stainless Steel, Weld. J., 1982, 61(3), p 82-93

11. J.A. Brook, Effect of Alloy Modifications on HAZ Cracking of A-286 Stainless Steel, Weld. J., 1974, 53(11), p 517-523

12. C.D. Lundin and P.W. Turner, Effect of the Hot Cracking of Uranium Weld Metal-Part I, Weld. J., 1970, 49(12), p 579-587

13. K.H. Tseng and C.P. Chou, Effect of Pulsed Gas Tungsten Arc Welding on Angular Distortion in Austenitic Stainless Steel Weldments, Sci. Technol. Weld. Joining, 2001, 6(3), p 149-153 
14. K.H. Tseng and C.P. Chou, The Effect of Pulsed GTA Welding on the Residual Stress of a Stainless Steel Weldment, J. Mater. Process. Technol., 2002, 123, p 346-353

15. V.I. Pavlovsky and K. Masubuchi, Research in the U.S.S.R. on Residual Stresses and Distortion in Welded Structures, Weld. Res. Counc. Bull., 1994, 338, p 44-48
16. K.H. Tseng and C.P. Chou, Effect of Nitrogen Addition to Shielding Gas on Residual Stress of Stainless Steel Weldments, Sci. Technol. Weld. Joining, 2002, 7(1), p 57-62

17. M.H. Chen and C.P. Chou, Effect of Thermal Cycles on Ferrite Content of Austenitic Stainless Steel, Sci. Technol. Weld. Joining, 1999, 4(1), p $58-62$ 